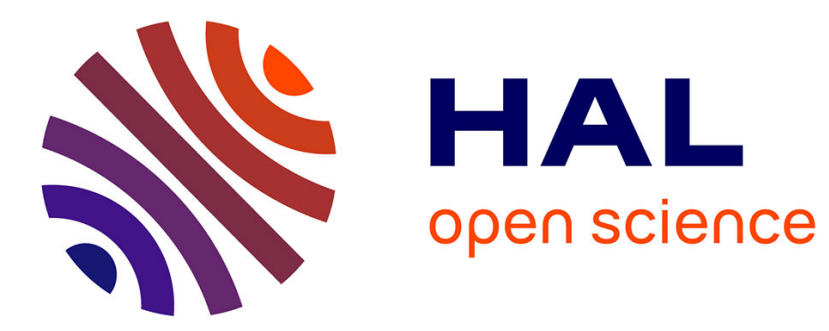

\title{
Precision electron beam exposure system, EB52
}

\author{
G. Tatsuno, M. Fujinami, A. Iwata, K. Kinamari
}

\section{To cite this version:}

G. Tatsuno, M. Fujinami, A. Iwata, K. Kinamari. Precision electron beam exposure system, EB52. Revue de Physique Appliquée, 1978, 13 (12), pp.705-708. 10.1051/rphysap:019780013012070500 . jpa-00244530

\section{HAL Id: jpa-00244530 https://hal.science/jpa-00244530}

Submitted on 1 Jan 1978

HAL is a multi-disciplinary open access archive for the deposit and dissemination of scientific research documents, whether they are published or not. The documents may come from teaching and research institutions in France or abroad, or from public or private research centers.
L'archive ouverte pluridisciplinaire HAL, est destinée au dépôt et à la diffusion de documents scientifiques de niveau recherche, publiés ou non, émanant des établissements d'enseignement et de recherche français ou étrangers, des laboratoires publics ou privés. 


\title{
SILICON PROCESSING II.
}

\section{PRECISION ELECTRON BEAM EXPOSURE SYSTEM, EB52}

\author{
G. TATSUNO, M. FUJINAMI, A. IWATA and K. KINAMARI
}

Musashino Electrical Communication Laboratory, N.T.T., 9-11, Midoricho 3-chome, Musashino-shi, Tokyo, 180, Japan

\begin{abstract}
Résumé. - Un système d'exposition de rayon électronique précis, EB52, est développé pour masquer et aussi pour l'exposition directe de cachet pour la pointure minimum de configuration moins que $2 \mu \mathrm{m}$. On présente la méthode de contrôle du système et le fonctionnement de composant du système qui est projeté considérant le facteur d'erreur de position. On présente aussi un exemple de la fabrication du masque chrome par EB52, dans lequel l'exactitude au-dessus $\pm 0,2 \mu \mathrm{m}$ est réalisée avec la correction distortion détournée et la correction de rayon rüsé employant la marque standard sur l'étape X-Y.
\end{abstract}

Abstract. - A precision electron beam exposure system, EB52, has been developed for mask making and direct wafer exposure for less than $2 \mu \mathrm{m}$ minimum pattern size. This paper describes the system control method and performance of the system components which are designed considering positioning error factors, and an example of chrome mask fabrication by the system, in which overlay accuracy of $\pm 0.2 \mu \mathrm{m}$ has been achieved with deflection distortion correction and beam shift correction using a standard mark on the $\mathrm{X}-\mathrm{Y}$ stage.

1. Introduction. - To fabricate high speed, low power and economical large scale integrated devices, researches on the design, fabrication and inspection technologies have been systematically carried out in the Electrical Communication Laboratories, NTT. The E/B system, EB52, was developed in the course of this research to fabricate a mask with a $1 \mu \mathrm{m}$ minimum linewidth $[1,2]$. Up to this time, many papers related to E/B systems mainly described system architecture or application for device fabrication $[3,4,5]$.

The intent of the present paper is not to give such subjects, but rather to describe system control methods and design of positioning error factors.

2. System design considerations. - In developing EB52, the authors focused mainly on mask fabrication and also on direct wafer exposure. Table I shows the design goal. Attaining this design goal, Gaussian spot beam vector scan method was adopted for three reasons :

\section{TABLE I}

\section{Design goal}

\section{Substrate}

Minimum feature size

Accuracy

Throughput

Beam

Scan speed

Input data

Software
$2 \sim 4$ inch mask blanks

$1.1 / 4 \sim 3$ inch wafer

$1 \mu \mathrm{m}$ square

$\pm 0.2 \mu \mathrm{m}$ overall

$60 \mathrm{~min} / 4$ inch mask

$20 \mathrm{kV} 10 \mathrm{nA}-0.25 \mu \mathrm{m}$ diam.

$0.001 \sim 4 \mathrm{~m} / \mathrm{s}$

PG 3000 format or special

EB format

system control, data edition
1) For $1 \mu \mathrm{m}$ linewidth fabrication, a spot beam is suitable.

2) For less than $2 \mu \mathrm{m}$ linewidth, proximity effect correction is important. Vector scan method is suitable for that purpose.

3) Vector scan method has the advantage to compensate positioning error due to wafer deformation in direct exposure.

Table II shows positioning error factors, counterplans and error distribution for the system. Assuming these error factors to be independent of each other, system control method and system components specifications are determined in order to satisfy the total positioning accuracy within the design goal.

Positioning error factors differ between mask exposure and direct wafer exposure. The dominant error factors in mask exposure are deflection distortion, beam position and $\mathrm{X}-\mathrm{Y}$ stage position errors. Deflection distortion correction and beam shift correction are carried out by laser interferometer and a standard mark on the X-Y stage. The X-Y stage position is measured by laser interferometer. The dominant errors in direct wafer exposure are due to wafer loading and wafer deformation in the fabrication process. These errors are detected by utilizing fiducial marks on the wafer and also an optical displacement detector, the " $Z$ sensor ». The total amount of wafer bowing that can be compensated is $\pm 100 \mu \mathrm{m}$.

Figure 1 shows a blockdiagram of EB52. Pattern data processing, for example compensation for proximity effect or data format conversion, is carried out by general purpose large computer, so the control computer load is reduced. 
TABLE II

System design guideline concerning error factors

\section{System component}

Electron opti- beam positioning error cal column deflection distortion

deflection response error

beam current deviation high voltage drift

Circuitry nonlinearity

blanking timing error

noise

drift

$\mathrm{X}-\mathrm{Y}$ stage $\quad$ stage positioning error heat transformation

residual magnetic field

yawing

vibration

Specimen

Total error
Error

distribution

$\overline{0.15} \mu \mathrm{m}$

$\pm 0.15 \mu \mathrm{m} \quad$ beam shift correction technique beam drift suppression

$\pm 0.025 \mu \mathrm{m}$ deflection distortion correction technique

low distortion deflection coil development

$\pm 0.025 \mu \mathrm{m}$ eddy current suppression, optimization of waiting time

$\pm 0.05 \mu \mathrm{m} \quad$ stabilized gun development

$\pm 0.025 \mu \mathrm{m}$ stabilized source development

$\pm 0.025 \mu \mathrm{m}$ high precision DAC development

$\pm 0.01 \mu \mathrm{m} \quad$ high speed and high accuracy analog comparator development

$\pm 0.01 \mu \mathrm{m} \quad$ band width optimization

$\pm 0.01 \mu \mathrm{m} \quad$ compensation for drift

$\pm 0.02 \mu \mathrm{m} \quad$ watching by laser interferometer

$\pm 0.08 \mu \mathrm{m} \quad$ use of low expansion materials, keep top table's temperature constant

$\pm 0.05 \mu \mathrm{m} \quad$ use of non-magnetic materials except for permalloy shields

$\pm 0.02 \mu \mathrm{m} \quad$ precision guide development

$\pm 0.04 \mu \mathrm{m} \quad$ real time feedback

$\pm 0.4 \mu \mathrm{m}$

$$
\begin{gathered}
\pm 0.2 \mu \mathrm{m} \\
(\text { mask) } \\
\pm 0.45 \mu \mathrm{m} \\
\quad \text { (wafer) }
\end{gathered}
$$

compensation by mark detection and optical displacement detection by « $\mathrm{Z}$ sensor »

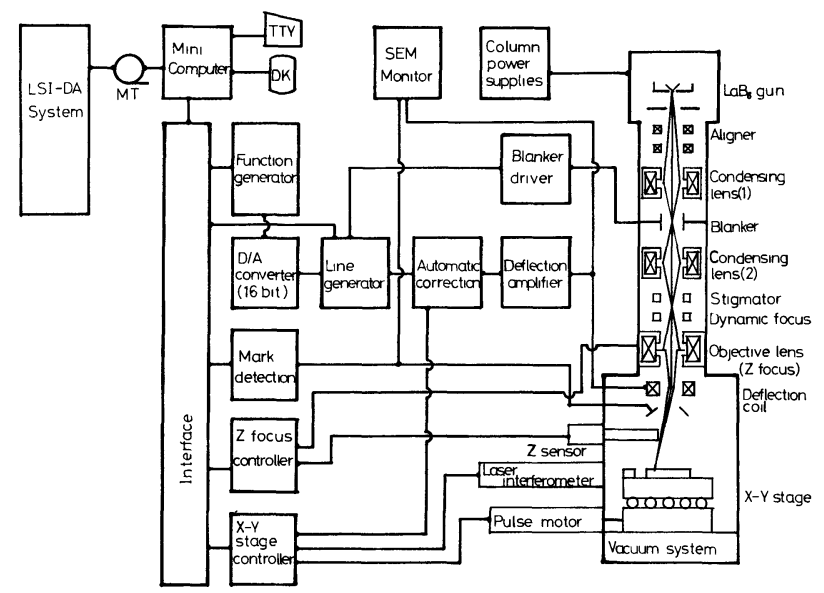

Fig. 1. - EB52 control system blockdiagram.

3. Electron optical column. - The electron optical column design objective is to obtain stabilized beam position and current with high resolution capability.
The column design is based on the conventional Gaussian spot beam concept. The probe forming system is composed of a lanthanum hexaboride gun followed by three magnetic lenses and a post-lens deflection coil. The nominal performance of the column is $2 \mathrm{~mm}$ square field size, $0.25 \mu \mathrm{m}$ beam diameter and $10 \mathrm{nA}$ beam current.

To achieve high precision beam positioning, special attention is given to the problem of beam drifts. Specially designed blanking apertures allow beam trajectories not to be affected by charge-up effects caused by aperture contamination. In addition, to suppress the effects of eddy current in metallic components adjacent to the deflection coil, these components are replaced by non-metallic materials coated with conductive film.

4. Deflection control circuit. - The circuitry used to generate precision analog vector scan signals is composed of a 16 bit digital-analog converter (DAC) and a line generator (LG) for each deflection axis. 
To draw pattern elements, combination of LG and DAC produces ramp signal for one axis and pointby-point signal for the other axis. The 16 bit DAC with self-calibration capability on the basis of a high precision digital voltmeter, as shown in figure 2, achieved $\pm 7.5 \mathrm{ppm}$ linearity and $0.5 \mu$ s settling time.

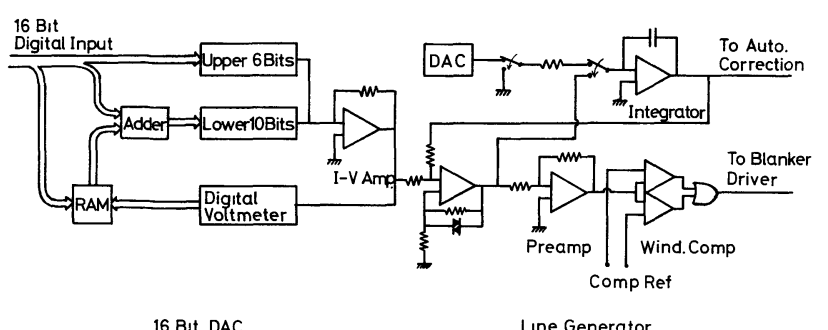

FIG. 2. - Analog part of deflection controller.

The LG has two functional modes, point-by-point mode for very small patterns and ramp mode for the others, which are selected by analog switches. The blanking trigger signal is produced by an analog comparator, as shown in figure 2 . The blanking signal timing error is minimized by adjusting comparator reference and employing a preamplifier with the analog comparator.

Registration errors are corrected by a small correction signal calculated in a deflection distortion correction procedure.

Bandwidth of the circuit used in the system is limited at about $1 \mathrm{MHz}$, to reduce high frequency noise.

5. X-Y stage control. - The X-axis driving motor is mounted on the $\mathrm{Y}$-axis slide, because simpler mechanical structure takes advantage of achieving high precision. Great care has to be taken to minimize yawing and other error factors, which are unmeasurable by a two-axis interferometer. Friction dampers are employed to settle the stage immediately after rapid steps to a new field site. Non-magnetic materials are used to avoid the effect of residual magnetic field. The top table, made of low expansion materials, is water cooled to keep the temperature constant.

6. Mask fabrication. - A pattern for $10 \times 10$ chips of a $64 \mathrm{k}$ bit MOS RAM was defined on a 4 inch chrome mask blank. The overall pattern (chip) dimension is approximately $6 \mathrm{~mm}$ square, which is divided into $3 \times 4$ scanning fields. The resist used on this mask fabrication is a negative-working polymer of polyglycidyl methacrylate (PGMA : $5 \times 10^{-7} \mathrm{C} / \mathrm{cm}^{2}$ ). Beam conditions are $5 \mathrm{nA}, 0.3 \mu \mathrm{m}$ diameter, $5 \times 10^{5} \mathrm{~A} / \mathrm{cm}^{2} / \mathrm{sr}$ brightness, and $2 \mathrm{~m} / \mathrm{s}$ spot velocity.

Stage temperature deviation has been controlled to less than \pm 0.02 degrees throughout each mask fabrication. Furthermore, beam current drift and beam diameter drift were held to less than $\pm 1 \%$ per hour and $\pm 0.1 \mu \mathrm{m}$ per hour, respectively, without control. The beam position drift was suppressed within $\pm 0.1 \mu \mathrm{m}$ per one compensation cycle, as shown in figure 3. Deflection distortion correction was performed only once when the system was set up. The average time for the exposure was $48 \mathrm{~min} / \mathrm{mask}$.

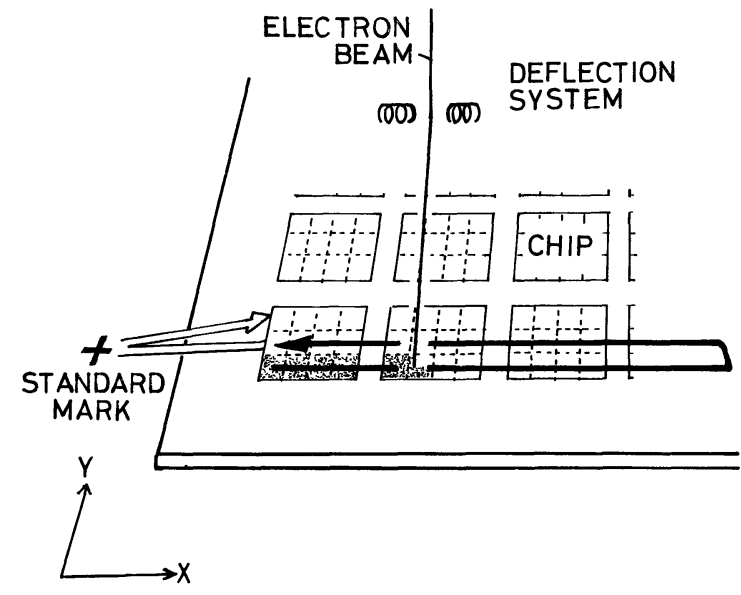

FIG. 3. - Substrate writing procedure.

Figure 4 shows typical overlay accuracy among three different level masks. This accuracy was obtained by measuring the location of corresponding pattern on each chip by NIKON Laser Interferometric X-Y Coordinate Measuring System. Field stitching error is negligibly small, compared with overlay error. $97 \%$ overlay accuracy of $\pm 0.2 \mu \mathrm{m}$ has been achieved.

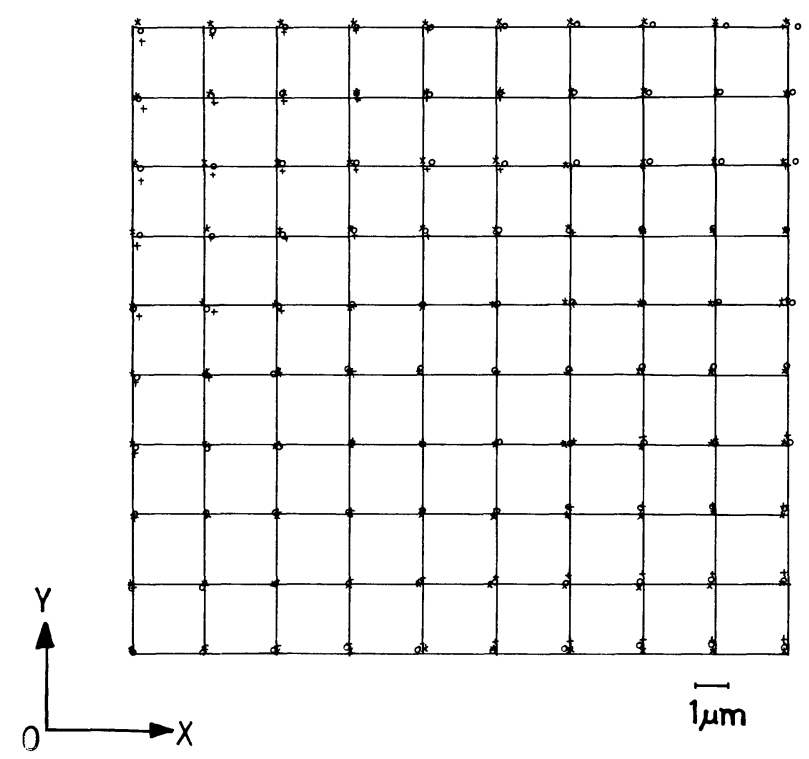

FIG. 4. - Overlay accuracy. $\mathrm{O}=\operatorname{mask} \mathrm{A}, \quad+=\operatorname{mask} \mathrm{B}$, $*=$ mask C. Node distance $X=6140 \mu \mathrm{m}, \mathrm{Y}=5820 \mu \mathrm{m}$.

7. Conclusion. - A precision E/B system, EB52, employing analog vector scan and Gaussian spot beam, has been described. It has been demonstrated that $\pm 0.2 \mu \mathrm{m}$ overlay accuracy has been achieved by deflection distortion correction and beam shift correction, using a standard mark on the $\mathrm{X}-\mathrm{Y}$ stage. 
Acknowledgments. - The authors would like to acknowledge the many valuable comments and encouragement of Dr. H. Toyoda and also like to thank the members of Technology Division of Musashino ECL and Hitachi Central Research Laboratory for their help in developing the system and mask making.

\section{References}

[1] HAYASHI, T., 8th International Conference on Electron and Ion Beam Science and Technology, Seattle, May 1978.

[2] Fujinami, M. et al., Rev. ECL, to be published in Jan. 1979.

[3] Herriott, D. S. et al., IEEE Trans. ED 22 (1975) 385.
[4] Yourke, H. S. et al., Tech. Digest IEDM (1976) 431.

[5] ChANG, T. H. P. et al., 7th International Conference on Electron and Ion Beam Science and Technology, Palo Alto, May 1976. 